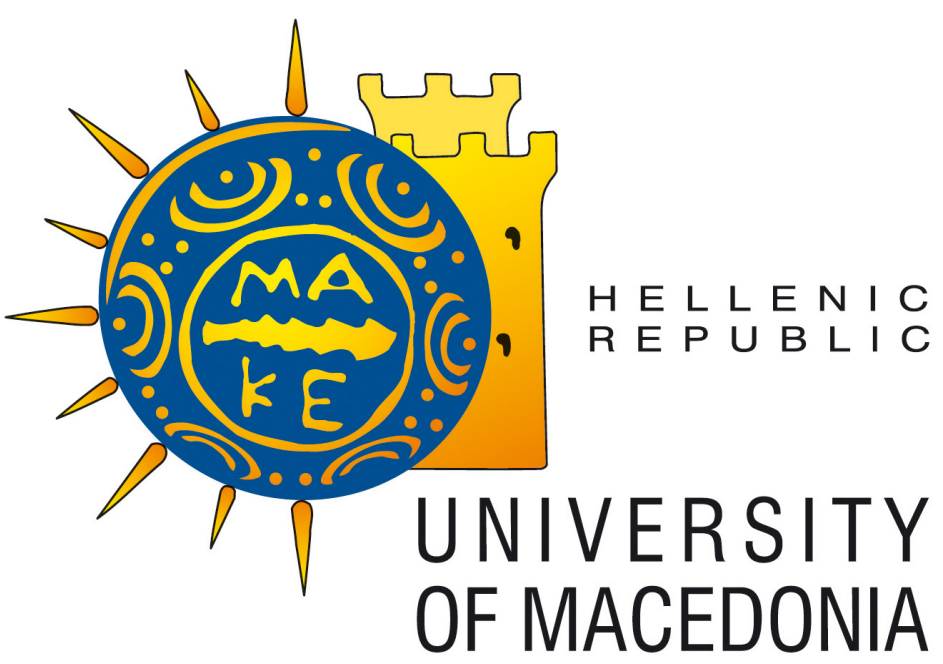

ISSN 1791-3144

\author{
University of Macedonia \\ Department of Economics
}

Discussion Paper Series

\title{
Estimating Residential Demand for Electricity in the United States, 1965-2006
}

Theologos Dergiades and Lefteris Tsoulfidis

\section{Discussion Paper No. 19/2008}




\title{
Estimating Residential Demand for Electricity in the United States, 1965-2006
}

\section{Theologos Dergiades* and Lefteris Tsoulfidis**}

\begin{abstract}
This paper examines the residential demand for electricity in the US economy as a function of the per capita income, the price of electricity, the price of oil for heating purposes, the weather conditions and the stock of occupied housing over the period 1965-2006. This paper has two novelties: first, the occupied stock of houses as a proxy for the stock of electrical appliances and second the identification of a possible equilibrium relationship among the variables is ascertained through the recently advanced ARDL approach to cointegration. Our empirical findings give support to a stable longrun relationship implying also short-run and long-run elasticities whose size and sign are comparable to other similar studies.
\end{abstract}

JEL Classification: C22, Q41, Q43

Keywords: Electricity Demand, ARDL, Cointegration

*Department of Economics, University of Macedonia, 156 Egnatia Street, PO Box 1592 54006 Thessaloniki, Greece, email: dergiades@uom.gr

** Corresponding author, Department of Economics, University of Macedonia, 156 Egnatia Street, PO Box 159254006 Thessaloniki, Greece, email: lnt@uom.gr 


\section{Introduction}

The residential demand for electricity and its determinants are of crucial importance for the contemplation of energy policy of an economy. The idea is that the supply of electricity requires the operation of electricity-generating plants which are costly to construct and also take considerable time (approximately 4 to 10 years) to have them operational. As a result, knowledge of the determinants of the demand for electricity as well as its accurate forecasting are of extreme importance for the contemplation of an effective energy policy to meet the current needs of population and, at the same time, to anticipate its future needs. Furthermore, the energy policy at the local and national level is associated with political debates because of environmental concerns. However, having a more precise knowledge of the determinants of demand and their impact we can make more informed decisions.

The issue of critical importance for all of the above is the nature of the electricity demand, that is, whether it is stable or not. A stable demand function indicates that there is a theoretical relationship between the variables involved and so policy proposals can be designed for meeting the current and future demand for electricity. By contrast, an unstable demand would indicate the failure to design any meaningful energy policy or reliable forecasting of future demand for electricity. The first econometric studies, starting from the pioneering cross-sectional study of demand for electricity in the UK of Houthakker (1951) simply assumed the presence of a stable demand function. Furthermore, he showed, contrary to the popular belief, that the demand for electricity was quite sensitive to both changes in prices and income. The first comprehensive study of the residential demand for electricity was conducted by Fisher and Kaysen (1962), who estimated electricity demand by households in both the short and the long-run. In their short-run model, Fisher and Kaysen (1962) used data on stocks of appliances and included not only the level but also the change in the stock of electrical appliances as well as their utilization rates. However, the quality of these data, according to Fisher and Kaysen (1962), ranged "from somewhat below the sublime to a bit above the ridiculous". This situation made many researchers to focus their efforts on partial-adjustment models, where the actual use of electricity might differ from the normal (desired) electricity consumption in the short-run. The difference might be due to the fact that the stock of electrical equipment does not adjust automatically. Another problem with the stock of electrical appliances was noticed by Bohi (1981), who argued that the presence of a possible aggregation bias might be emanating from the different utilization rates of 
electrical appliances as well as their different price and income effects. As a result, one by just taking the averages of these variables it is very likely to commit an aggregation bias.

These types of studies were improved in the recent decades by using more reliable time series data spanning a longer period of time and also explicitly addressing the issue of the stability of electricity demand using unit root tests and the nowadays popular cointegration technique. In fact, this econometric technique was developed in the pioneering works of Engle and Granger (1987) and in their efforts to deal with the spurious regressions which arise when variables that are driven by time trends appear to be correlated in finite sample regression, even though no true relationship exists among them. Furthermore, since the economic variables employed in the electricity demand equation, such as per capita income, prices of electricity and oil as the close substitute product, the stock of housing or electrical appliances and so forth, are likely to be endogenous. As a result, in estimating electricity demand by a single equation it is possible to produce simultaneous bias and hence lead to unreliable forecasts. Both problems can be dealt effectively with the help of the cointegration technique which is especially useful to identify the presence of a stable and, therefore, a long-term equilibrium relationship among the variables. In this sense, the present paper uses the recently advanced Autoregressive Distributed Lag (ARDL) approach to cointegration as proposed by Pesaran et al. (2001).

The remainder of the paper is structured as follows: Section 2 provides the econometric specification of the model for electricity demand for the US economy and discusses the ARDL cointegration technique and its advantages over the standard ones. Section 3 presents the data and evaluates the results of the econometric analysis. Finally, Section 4 makes some concluding remarks and suggestions for future research efforts.

\section{Model and methodology}

In what follows we use a Cobb-Douglas type of demand function to describe residential electricity consumption in the US (Silk and Joutz, 1997) and has the following representation:

$$
C_{e, t}=A Y_{t}^{a_{1}} P_{e, t}^{a_{2}} \mathrm{CH}_{t}^{a_{3}} P_{o, t}^{a_{4}} S_{t}^{a_{5}} e^{\varepsilon_{t}}
$$

where, $C_{e}$ is the per capita consumption of electricity in $\mathrm{KWh}, A$ is the drift term, $Y$ is the real per capita income, $P_{e}$ is the real average residential price of electricity, $\mathrm{CH}$ is the cooling and degrees-days index, $P_{o}$ is the average price of oil for heating purposes; $S$ is 
the per capita occupied stock of housing, $e$ is the neperian number, $\varepsilon$ is the random error term and finally $a_{1}, a_{2}, a_{3}, a_{4}$ and $a_{5}$, are parameters to be estimated. By taking natural logarithms from both sides of (1), we arrive at the following econometric specification ${ }^{1}$ :

$$
c_{e, t}=a_{o}+a_{1} y_{t}+a_{2} p_{e, t}+a_{3} c h_{t}+a_{4} p_{o, t}+a_{5} s+\varepsilon_{t}
$$

According to economic theory, the income elasticity and the cross-price elasticity for a competitive product, such as oil, are expected to be positive, while the price elasticity of electricity demand is expected to be negative. The sign of the cooling and heating degrees-days elasticity is expected to be positive, since positive or negative deviations from the mean temperature are associated with the need of cooling or heating, respectively. Cooling or heating is achieved, to great extent, through the utilization of electricity-using appliances such as air-conditions or baseboard heaters, hence, electricity consumption increases.

The contribution of our study compared to other similar ones which are trying to model the demand for residential electricity (see for example Zahariadis and Pashourtidou, 2007; Halicioglu, 2007; Narayan and Smyth, 2005; Kamerschen and Porter, 2004; Hondroyiannis, 2004), is the use of the per capita occupied stock of housing as proxy for the per capita stock of electricity-using appliances. Since residential electricity consumption depends on the stock of electricity-using equipment, our basic assumption is that electricity-using equipment should be linked intrinsically to the stock of occupied dwellings. The rationale for such linkage is that all dwellings since the midsixties are equipped with electricity-using appliances in order to offer typical conveniences to the residents and furthermore, dwellings use electricity for lighting purposes which is not an insignificant component of total electricity consumption, which cannot be captured by the stock of household appliances that has been commonly employed in similar studies. Thus, it can be argued that, other things equal, the higher the number of occupied stock of houses, the higher the stock of electricity-using appliances and therefore the higher the consumption of electricity ${ }^{2}$.

\footnotetext{
${ }^{1}$ Lower case letters denote that the variables are expressed in logarithms.

${ }^{2}$ As an alternative variable we used the number of marriages, a variable also strictly associated with the purchase of household electrical appliances. The results that we received were similar to those of the stock of dwellings. The use of an index of urbanization, which has been routinely employed for developing economies, would not be appropriate for an advanced economy such as the US. In fact, we experimented with the variable urbanization and we found that in the case of the US economy and for the time period of our study has a negative elasticity.
} 
Equation (2) can be seen as a long-run equilibrium relationship which would be extracted through the application of cointegration technique revealing this way the dynamic interactions among the variables under consideration. Given all the available univariate and multivariate techniques for cointegration the most suitable method in our case is the ARDL bounds-testing procedure. The decisive criterion for the selection of the ARDL cointegration technique over the alternative Johansen technique (Johansen, 1988 ) is that it can be easily applied even in the case where the variables of the model are of mixed order of integration, that is to say they are $\mathrm{I}(0)$ and $\mathrm{I}(1)$ (Pesaran and Pesaran, 1997, pp. 302-303) ${ }^{3}$. We opted for the ARDL approach to cointegration because of its simplicity and its suitability to models where the involved variables are of mixed order of integration. The major drawback of the ARDL approach to cointegration is that it fails to provide robust results in the presence of $\mathrm{I}(2)$ variables.

To ascertain the existence of a long-run relationship within the framework of the ARDL approach, the first step is to estimate the following unrestricted error correction model by Ordinary Least Squares (OLS):

$$
\begin{aligned}
\Delta c_{e, t}= & a_{o}+\sum_{i=1}^{n} a_{1 i} \Delta c_{e, t-i}+\sum_{i=1}^{n} a_{2 i} \Delta y_{t-i}+\sum_{i=1}^{n} a_{3 i} \Delta p_{e, t-i}+\sum_{i=1}^{n} a_{4 i} \Delta c h_{t-i}+\sum_{i=1}^{n} a_{5 i} \Delta p_{o, t-i}+ \\
& \sum_{i=1}^{n} a_{6 i} \Delta s_{t-i}+a_{7} c_{e, t-1}+a_{8} y_{t-1}+a_{9} p_{e, t-1}+a_{10} c h_{t-1}+a_{11} p_{o, t-1}+a_{12} s_{t-1}+\varepsilon_{1 t}
\end{aligned}
$$

The second step is to test the joint hypothesis that the long-run multipliers of the lagged level variables are all equal to zero, against the alternative that at least one is nonzero. In the presence of cointegration one should reject the null hypothesis. It has to be mentioned that the F-statistic obtained by performing the Wald test has a non-standard distribution, whose asymptotic critical values are provided by Pesaran et al. (2001) . Nevertheless, as it is argued by Narayan (2005), these critical values are inappropriate whenever the sample size is small, or in other words when annual macroeconomic variables are involved. Narayan (2005) provides a set of critical values for samples ranging from 30 to 80 observations for the well established levels of significance.

Having identified the existence of a cointegration relationship the next step would be the selection of the optimal ARDL specification of equation (2) on the basis of a set

\footnotetext{
3 Situations such as ours are exceedingly difficult to be dealt within the Johansen's approach to cointegration, for a succinct critique of this method see Harris (1995).

4Pesaran et al. (2001) generated critical values are based on samples of 500 and 1000 observations.
} 
of criteria (e.g. Schwarz or Akaike). A general specification for the ARDL $\left(p_{1}, q_{1}, q_{2}, q_{3}, q_{4}, q_{5}\right)$ model is presented below:

$$
c_{e, t}=b_{o}+\sum_{i=1}^{p_{1}} b_{1 i} c_{e, t-i}+\sum_{i=0}^{q_{1}} b_{2 i} y_{t-i}+\sum_{i=0}^{q_{2}} b_{3 i} p_{e, t-i}+\sum_{i=0}^{q_{3}} b_{4 i} c h_{t-i}+\sum_{i=0}^{q_{4}} b_{5 i} p_{o, t-i}+\sum_{i=0}^{q_{5}} b_{6 i} s_{t-i}+u_{t}(4)
$$

The long-run multipliers can be obtained as non-linear functions of the parameter estimates of equation (4). ${ }^{5}$ In particular, the long run multipliers will be:

$$
a_{o}=b_{o} /\left(1-\sum_{i}^{p_{1}} b_{1, i}\right) \text { and } a_{j}=b_{m} /\left(1-\sum_{i}^{p_{1}} b_{1, i}\right), \text { with } j=1, \ldots, 5 \text { and } m=2, . ., 6
$$

The final step is to estimate the short-run dynamic coefficients for the optimal ARDL model via the following error correction model:

$$
\begin{aligned}
\Delta c_{e, t}= & d_{o}+\sum_{i=1}^{p_{1}} d_{1 i} \Delta c_{e, t-i}+\sum_{i=1}^{q_{1}} d_{2 i} \Delta y_{t-i}+\sum_{i=1}^{q_{2}} d_{3 i} \Delta p_{e, t-i}+\sum_{i=1}^{q_{3}} d_{4 i} \Delta c h_{t-i}+\sum_{i=1}^{q_{4}} d_{5 i} \Delta p_{e, t-i}+ \\
& \sum_{i=1}^{q_{5}} d_{6 i} \Delta s_{t-i}+d_{7} E C_{t-1}+e_{t}
\end{aligned}
$$

where, $E C_{t-1}$ is the error correction term resulting from the verified long-run equilibrium relationship and $d_{7}$ is a parameter indicating the speed of adjustment to the equilibrium level after a shock. Moreover, Pesaran and Pesaran (1997) argued that it is extremely important to ascertain the constancy of the long-run multipliers by testing the above error-correction model for the stability of its parameters. The commonly used tests for this purpose are the cumulative sum (CUSUM) and the cumulative sum of squares (CUSUMQ), both of which have been introduced by Brown et al., (1975).

By completing the preceding analysis and given the presence of a long-run equilibrium relation, the existence of causality in at least one direction is expected, to this end we apply the Granger causality test (Granger, 1969) augmented by the errorcorrection term. In cases where equilibrium is verified, the inclusion of the errorcorrection term is essential since otherwise inferences based on the estimated VAR system in first differences will be of an ambiguous quality (Engle and Granger, 1987). In

${ }^{5}$ Standard errors for the long-run multipliers can be computed using the delta method. For a more detailed discussion of these issues see Bentzen and Engsted (2001). 
our case, the general form of the pth-order vector error-correction model is given by equation (7):

$$
\left[\begin{array}{l}
\Delta c_{e, t} \\
\Delta y_{t} \\
\Delta p_{e, t} \\
\Delta c h_{t} \\
\Delta p_{o, t} \\
\Delta s_{t}
\end{array}\right]=\left[\begin{array}{l}
\theta_{1} \\
\theta_{2} \\
\theta_{3} \\
\theta_{4} \\
\theta_{5} \\
\theta_{6}
\end{array}\right]+\sum_{i=1}^{p}\left[\begin{array}{llllll}
\varphi_{11 i} & \varphi_{12 i} & \varphi_{13 i} & \varphi_{14 i} & \varphi_{15 i} & \varphi_{16 i} \\
\varphi_{21 i} & \varphi_{22 i} & \varphi_{23 i} & \varphi_{24 i} & \varphi_{25 i} & \varphi_{26 i} \\
\varphi_{31 i} & \varphi_{32 i} & \varphi_{33 i} & \varphi_{34 i} & \varphi_{35 i} & \varphi_{36 i} \\
\varphi_{41 i} & \varphi_{42 i} & \varphi_{43 i} & \varphi_{44 i} & \varphi_{45 i} & \varphi_{46 i} \\
\varphi_{51 i} & \varphi_{52 i} & \varphi_{53 i} & \varphi_{54 i} & \varphi_{55 i} & \varphi_{56 i} \\
\varphi_{61 i} & \varphi_{62 i} & \varphi_{63 i} & \varphi_{64 i} & \varphi_{65 i} & \varphi_{66 i}
\end{array}\right]\left[\begin{array}{l}
\Delta c_{e, t-i} \\
\Delta y_{t-i} \\
\Delta p_{e, t-i} \\
\Delta c h_{t-i} \\
\Delta p_{o, t-i} \\
\Delta s_{t-i}
\end{array}\right]+\left[\begin{array}{l}
\lambda_{1} E C_{t-1} \\
\lambda_{2} E C_{t-2} \\
\lambda_{3} E C_{t-3} \\
\lambda_{4} E C_{t-4} \\
\lambda_{5} E C_{t-5} \\
\lambda_{6} E C_{t-6}
\end{array}\right]+\left[\begin{array}{l}
v_{1 t} \\
v_{2 t} \\
v_{3 t} \\
v_{4 t} \\
v_{5 t} \\
v_{6 t}
\end{array}\right](7)
$$

\section{Data and Empirical results}

The data used in this paper are annual time series spanning the period 1965 to 2006. The source of our data on gross domestic product in constant prices and total population series is the World Development Indicators (WDI) database ${ }^{6}$. Residential electricity consumption in thousands of $\mathrm{KWh}$, average real retail prices of electricity in cents per KWh for the residential sector, the real prices of oil for heating purposes and the cooling and heating degrees-days indexes ${ }^{7}$ were obtained from the Energy Information Administration (EIA) database. Finally, the series for the occupied stock of housing ${ }^{8}$ were retrieved from the database offered by the US census bureau.

In order to exclude the possibility of dealing with $\mathrm{I}(2)$ variables, which do not allow the use of the ARDL approach to cointegration, we performed the Augmented Dickey-Fuller (ADF) test to verify the exact order of integration of the variables involved. Table 1 below displays the results according to which the set of variables used in our study is a mixture of $\mathrm{I}(0)$ and $\mathrm{I}(1)$.

\footnotetext{
${ }^{6}$ For details see http://www.devdata.worldbank.org/dataonline.

${ }^{7}$ Cooling and heating degrees-days indexes are defined as deviations above or below the mean daily temperature of $65^{\circ} \mathrm{F}$. For example, a mean daily temperature of $60^{\circ} \mathrm{F}$ is translated to 5 heating degreesdays while a temperature of $71^{\circ} \mathrm{F}$ is translated to 6 cooling degrees-days. The source of our data is http://www.eia.doe.gov.

8 The stock of housing refers to the stock of permanent dwellings. A dwelling is a self-contained unit of accommodation. Self-containment is where all the rooms (in particular the basic facilities i.e., kitchen, bathroom and toilet) are behind a door that only the household can use. A dwelling can therefore contain a single household or a number of households, which share at least one of the basic facilities, but do not share living accommodation. The source of data is http://www.census.gov.
} 
Table 1: ADF tests

\begin{tabular}{|c|c|c|c|c|c|c|}
\hline \multicolumn{2}{|c|}{ level } & \multirow{2}{*}{$\mathrm{p}$-value } & \multicolumn{2}{|c|}{$1^{\text {st }}$ Differences } & \multirow{2}{*}{$\mathrm{p}$-value } & \multirow{2}{*}{$\begin{array}{c}\text { Order of } \\
\text { Integration }\end{array}$} \\
\hline Variable & ADF stat. & & Variable & ADF stat. & & \\
\hline$c_{e}$ & -1.7883 & 0.3802 & $\Delta c_{e}$ & -4.1609 & 0.0022 & $\mathrm{I}(1)$ \\
\hline$y$ & -0.4934 & 0.8822 & $\Delta y$ & -4.5298 & 0.0010 & $\mathrm{I}(1)$ \\
\hline$p_{e}$ & -2.4187 & 0.1441 & $\Delta p_{e}$ & -3.9822 & 0.0037 & $\mathrm{I}(1)$ \\
\hline$C h$ & -4.2763 & 0.0016 & $\Delta c h$ & - & - & $\mathrm{I}(0)$ \\
\hline$p_{o}$ & -1.5170 & 0.5148 & $\Delta p_{o}$ & -4.7770 & 0.0004 & $\mathrm{I}(1)$ \\
\hline$S$ & -0.0429 & 0.9542 & $\Delta s$ & -5.7069 & 0.0002 & $\mathrm{I}(1)$ \\
\hline
\end{tabular}

Notes: ADF stands for the Augmented Dickey-Fuller test. All level variables are in logs. $\Delta$ is the first difference operator.

Having estimated equation (3) by means of OLS, the ARDL approach to cointegration requires the testing of the following null hypothesis: $a_{7}=a_{8}=a_{9}=a_{10}=a_{11}=a_{12}$, against the alternative that at least one of these coefficients is different from zero. Given that the value of the F-statistic is sensitive to the number of lags imposed each time on the differenced variables (Bahmani-Oskooee and Goswami, 2003); we carried out the Wald-test by imposing one and two lags. The F-statistic that we obtained for the demand function was 5.1 for one lag and 6.2 for two lags. The results displayed in Table 2 confirm the existence of an equilibrium relationship in the case of one and two lags at the 0.01 and 0.05 levels of significance, respectively (see Table 2). For reasons of economy of space and clarity of presentation the demand function is written as $F_{C e}\left(C_{e} \mid Y, P_{\theta}, C H, P_{o}, S\right)$, the notation does not change when the demand function is normalized with respect to each and everyone of the independent variables. For example, the normalization on the real price of oil is denoted as $F_{P_{o}}\left(P_{o} \mid Y, P_{\ell}, C H, C_{\ell}, S\right)$. Moreover, in our effort to ensure that the independent variables can be treated as long-run forcing variables, we tested for other possible cointegration relationships. The results of the repeated testing procedure are presented in Table 2. Clearly, there is only one cointegration relationship no matter if one or two lags are imposed and that all the independent variables can be treated as long-run forcing variables for the per capita consumption of electricity.

Taking for granted the existence of a long-run equilibrium, equation (4) was estimated by setting the maximum lag-length to two and using the Schwarz Bayesian Criterion (SBC) for the selection of model's lag order. The specification finally selected was the ARDL $(2,0,0,0,2,0)$. The derived long-run elasticities resulting from the relationships of equation (5), along with a number of diagnostic tests for the underlying ARDL model are shown in Table 3. The estimated elasticities display the expected signs which are negative for the average price of electricity and positive for the rest of the variables and moreover all long-run elasticities are significant at the 0.02 level. The 
elasticities are interpreted as usual, for instance 1\% increase in the per capita occupied stock of housing leads, other things equal, to $1.5432 \%$ increase in the residential per capita consumption of electricity. Regarding the magnitude of price and income elasticities are within the bounds of previous studies, for example Bohi (1981) in a survey of 25 studies investigating the demand for residential electricity reports that the long-run price elasticity range between -0.45 and -2.1 , while the long-run income elasticity range between 0 and 2. Sutherland (1983) finds that the long-run price elasticity is greater than 1 and the long-run income elasticity less than 0.5 (see also other studies such as: Taylor, 1975; Taylor, 1977; Bohi and Zinnerman, 1984; Hogan, 1989 and Dahl, 1993). Finally, diagnostic tests for the underlying ARDL model verify that the residuals are normal, no serially correlated and non-heteroscedastic.

Table 2: Bounds Testing for Cointegration

\begin{tabular}{ccc}
\hline & \multicolumn{2}{c}{ F-Statistics } \\
\cline { 2 - 3 } Dependent variable & \multicolumn{2}{c}{ Alternative lag lengths } \\
\cline { 2 - 3 } & $5.1370^{* *}$ & $2.2215^{*}$ \\
$F_{C e}\left(C_{e} \mid Y, P_{e}, C H, P_{o}, S\right)$ & 0.6533 & 2.5059 \\
$F_{Y}\left(Y \mid C_{e}, P_{e}, C H, P_{o}, S\right)$ & 3.0899 & 3.0151 \\
$F_{P e}\left(P_{e} \mid Y, C_{e}, C H, P_{o}, S\right)$ & 2.2133 & 1.5219 \\
$F_{C H}\left(C H \mid Y, P_{e}, C_{e}, P_{o}, S\right)$ & 2.0509 & 1.4229 \\
$F_{P_{o}}\left(P_{o} \mid Y, P_{e}, C H, C_{e}, S\right)$ & 3.3171 & 3.3016 \\
$F_{S}\left(S \mid Y, P_{e}, C H, P_{o}, C_{e}\right)$ & &
\end{tabular}

Notes: The single and double star symbols denote the presence of cointegration at the level of 0.01 and 0.05 , respectively. For $\mathrm{n}=40$ and $\mathrm{k}=5$, the two associated pairs of critical values are 4.045-5.898 and 2.962-4.338, for 0.01 and 0.05 , respectively. The critical values were obtained from Narayan (2005), p.1988, case III.

Table 3: ARDL analysis

Panel A: Long-run coefficients for the ARDL $(2,0,0,0,2,0)$ model

\begin{tabular}{ccccccc}
\hline Variable & $c$ & $y$ & $p_{e}$ & $c h$ & $p_{o}$ & $s$ \\
\hline Coefficient & 1.1749 & 0.2728 & -1.0652 & 0.7264 & 0.1990 & 1.5432 \\
t-statistic & 0.6383 & 2.6411 & -5.6984 & 2.7102 & 3.6960 & 4.1710 \\
p-value & 0.5310 & 0.0130 & 0.0000 & 0.0110 & 0.0010 & 0.0000 \\
\hline
\end{tabular}

Panel B: Diagnostic tests of the underlying ARDL model

\begin{tabular}{ccc}
\hline $\begin{array}{c}\text { Lagrange Multiplier } \\
\text { Statistic }\end{array}$ & Statistic's Value & $p$-value \\
\hline Serial correlation & 2.2439 & 0.134 \\
Normality & 1.4345 & 0.488 \\
Heteroscedasticity & 0.0568 & 0.812 \\
\hline
\end{tabular}

Notes: The ARDL $(2,0,0,0,2,0)$ specification was selected based on the Schwarz Bayesian Criterion. The maximum lag length was set to 2 . 
The short-run dynamics of the equilibrium relationship are obtained via the relevant error correction model described in equation (6) and the results are presented in Table 4 below. As expected all short-run elasticities are lower in absolute value than those in the long-run and remain significant at the 0.05 level. The reason for this is that in the short-run because households demand is attached to the stocks of existing equipment, while in the long-run the stock of equipment itself changes. The lagged error correction term is statistically significant with the expected negative sign.

Table 4: The error-correction representation model

Panel A: Error-correction estimation results. $\Delta C_{e}$, is the dependent variable

\begin{tabular}{|c|c|c|c|c|c|c|c|c|c|}
\hline Variable & $c$ & $\Delta c_{e, t-1}$ & $\Delta y$ & $\Delta p_{e}$ & $\Delta c h$ & $\Delta p_{o}$ & $\Delta p_{o, t-1}$ & $\Delta s$ & $\mathrm{EC}_{t-1}$ \\
\hline Coefficient & 0.426 & -0.288 & 0.101 & -0.386 & 0.263 & 0.014 & -0.049 & 0.560 & -0.363 \\
\hline t-statistic & 0.601 & -2.515 & 2.611 & -3.775 & 3.164 & 0.601 & -2.100 & 2.554 & -5.053 \\
\hline$p$-value & 0.552 & 0.017 & 0.014 & 0.001 & 0.003 & 0.552 & 0.044 & 0.016 & 0.000 \\
\hline \multicolumn{10}{|c|}{ Panel B: Diagnostic Statistics } \\
\hline \multicolumn{2}{|c|}{$\mathrm{R}^{2}$-adjusted } & \multicolumn{3}{|c|}{0.7455} & \multicolumn{3}{|c|}{ Schwarz criterion } & \multicolumn{2}{|c|}{97.054} \\
\hline \multicolumn{2}{|c|}{ F-statistic } & \multicolumn{3}{|c|}{15.4078} & \multicolumn{3}{|c|}{ Akaike criterion } & \multicolumn{2}{|c|}{105.498} \\
\hline \multicolumn{2}{|c|}{ DW-statistic } & \multicolumn{3}{|c|}{2.1805} & \multicolumn{3}{|c|}{ RSS } & \multicolumn{2}{|c|}{0.007} \\
\hline
\end{tabular}

Notes: The error-correction term is given by:

$\mathrm{EC}=c_{e}-0.2728 * y+1.0652 * p_{e}-0.7264 * c h-0.1990 * p_{o}-1.5432 * s-1.1749 * c$.

$\mathrm{DW}$ is the Durbin-Watson statistic and RSS is the residual sum of squares.

In order to ensure the stability of the long-run parameters of our econometric specification, we applied the CUSUM and the CUSUMQ tests in the residuals of the error-correction equation (6). Figures 1 and 2 below, display the results of CUSUM and CUSUMQ tests, respectively. In both figures the dotted lines represent the critical upper and lower bounds at the 0.05 level of significance. The visual inspection of Figures 1 and 2 , reveals that there is no evidence of parameter instability, since the cumulative sum of the residuals and the cumulative sum of the squared residuals move within the critical bounds.
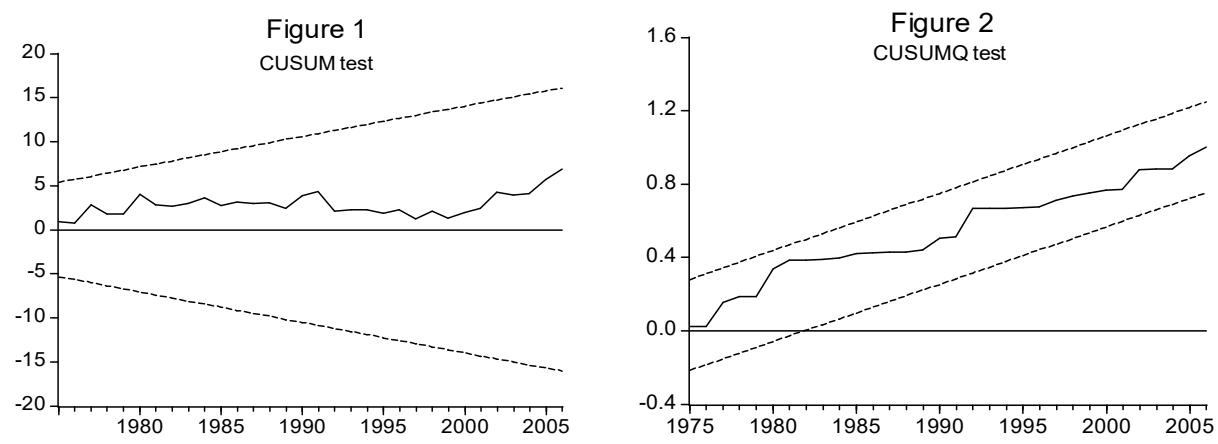
The ARDL bounds testing procedure that we employed, while it can confirm the existence or not of a long-run relationship, nevertheless, it cannot be used to ascertain the direction of temporal causality among the variables of our model. For this reason, we performed an augmented Granger causality test by incorporating the error correction term in the cointegration relationship. As a consequence, we estimated the pth-order vector error-correction model of equation (7) using two lags and adding the errorcorrection term only when the per capita consumption of electricity is the depended variable. The results in Table 5 suggest that in the long-run, all the variables of equation (2) Granger cause implicitly via the error correction term the per capita consumption of electricity; thereby, confirming the equilibrium suggested by the bounds testing procedure. Turning to the short-run, the results suggest the presence of unidirectional causality running, first, from the cooling-heating degrees-days and the real price of oil for heating purposes to the per capita consumption of electricity; second, from the real price of electricity and the real price of oil for heating purposes to the real per capita income and finally, from the real price of oil for heating purposes to the real price of electricity.

Table 5. Granger causality tests

\begin{tabular}{|c|c|c|c|c|c|c|c|}
\hline \multirow{3}{*}{ dependent } & \multicolumn{7}{|c|}{ F-Statistics } \\
\hline & \multicolumn{7}{|c|}{ Independent variables } \\
\hline & $\Delta c_{e}$ & $\Delta y$ & $\Delta p_{e}$ & $\Delta c h$ & $\Delta p_{o}$ & $\Delta s$ & $\mathrm{EC}_{t-1}$ \\
\hline$\Delta c_{e}$ & - & 0.358 & 1.713 & $5.369^{* *}$ & $9.291 *$ & 0.248 & $32.73^{*}$ \\
\hline$\Delta y$ & 1.759 & - & $7.869 *$ & 1.957 & $18.742 *$ & 3.432 & - \\
\hline$\Delta p_{e}$ & 0.033 & 0.331 & - & 0.740 & $9.015^{*}$ & 0.239 & - \\
\hline$\Delta c h$ & 0.032 & 0.190 & 0.466 & - & 1.845 & 0.310 & - \\
\hline$\Delta p_{o}$ & 0.029 & 1.880 & 0.113 & 0.165 & - & 0.128 & - \\
\hline$\Delta s$ & 1.808 & 2.166 & 2.476 & 0.003 & 0.037 & - & - \\
\hline
\end{tabular}

\section{Summary and Conclusions}

This paper has examined the determinants of the aggregate residential demand for electricity in the US economy. The econometric specification assumes that the demand for electricity depends on the price of electricity, the per capita income, the weather conditions, the price of substitute products such as oil and finally the stock of dwellings, a variable that has not been hitherto tested and purports to approximate the existing stock of electrical appliances. Furthermore and unlike previous studies of the US electricity demand by households, we tested the stability of our demand function using 
the newly advanced ARDL cointegration technique, which showed that there is a single cointegrating relation among the variables involved. The error correction model was consistent with the expectations about the signs of the short-run parameters and their magnitude which was found lower than their long-run counterparts. These results are particularly encouraging to continue our research along the same lines addressing questions of forecasting as well as the inclusion of various shocks in energy supply.

\section{References}

Bahmani-Oskooee, M.M. and Goswami, G.G. (2003). A disaggregated approach to test the J-curve phenomenon: Japan versus her major trading partners. Journal of Economics and Finance 27, 102-113.

Bentzen, J. and Engsted, T. (2001). A revival of the autoregressive distributed lag model in estimating energy demand relationships. Energy 26, 45-55.

Bohi, D.R. (1981). Analyzing Demand Behaviour: A Study of Energy Elasticities. Published for Resources for the Future by Johns Hopkins Press, Baltimore.

Bohi, D.R. and Zimmerman, M. (1984) An Update on Econometric Studies of Energy Demand. Annual Review of Energy 9, 105-154.

Brown, R.L., Durbin, J. and Evans, J.M. (1975). Techniques for testing the constancy of regression relationships over time. Journal of the Royal Statistical Society 37, 149-192

Dahl, C. (1993). A survey of energy demand studies in support of the development of NEMS. US Department of Energy.

Engle, R. and Granger, C. (1987). Cointegration and error correction representation: estimation and testing. Econometrica 55, 251-276.

Fisher, F. and Keysen, C. (1962). A Study in Econometrics: the Demand for Electricity in the United States. Amsterndam: North Holland.

Granger, C.W.J. (1969). Investigating causal relations by econometric models and crossspectral methods. Econometrica 37, 424-438.

Halicioglu, F. (2007). Residential electricity demand dynamics in Turkey. Energy Economics 29, 199-210.

Harris, R. (1995). Using Cointegration Analysis in Econometric modelling. Prentice Hall, London.

Hogan, W. W. (1989). A Dynamic Putty-Semi-putty Model of Aggregate Energy Demand. Energy Economics 11, 53-69. 
Hondroyiannis, G. (2004). Estimating residential demand for electricity in Greece. Energy Economics 26, 319-334.

Houthakker, H.S. (1951). Some Calculations on Electricity Consumption in Great Britain. Journal of the Royal Statistical Society 114, 359-371.

Johansen, S. (1988). Statistical analysis of cointegration vectors. Journal of Economic Dynamics and Control 12, 231-254.

Kamerschen, D.R. and Porter, D.V. (2004). The demand for residential, industrial and total electricity, 1973-1998. Energy Economics 26, 87-100.

Narayan P.K. (2005). The saving and investment nexus for China: evidence for cointegration tests. Applied Economics 37, 1979-1990.

Narayan P.K. and Smyth R. (2005). The residential demand for electricity in Australia: an application of the bounds testing approach to cointegration. Energy Policy 33, 467474.

Pesaran, M.H. and Pesaran, B. (1997). Working with Microfit 4.0: Interactive Econometric Analysis, Oxford University Press, Oxford.

Pesaran, M.H., Shin, Y. and Smith, R.J. (2001). Bounds testing approaches to the analysis of level relationships. Journal of Applied Econometrics 16, 289-326.

Silk, J.I. and Joutz, F.L. (1997). Short and long-run elasticities in US residential electricity demand: a co-integration approach. Energy Economics 19, 493-513

Sutherland, R. J. (1983). Instability of electricity demand functions in the post-oil embargo period. Energy Economics 5, 267-272.

Taylor, L.D. (1975). The Demand for Electricity: A Survey. Bell Journal of Economics 6, 74110.

Taylor, L.D. (1977). The Demand for Energy: A Survey of Price and Income Elasticities. In International Studies of the Demand for Energy, ed. By William D. Nordhaus, North Holland, Amsterdam.

Zachariadis, T. and Pashourtidou, N. (2007). An empirical analysis of electricity consumption in Cyprus. Energy Economics 29, 183-198. 